\title{
DESIGNING A SMALL LANGUAGE LABORATORY \\ FOR THE 1980's \\ James Gunn
}

\begin{abstract}
When Rockford College needed a new language laboratory, it was necessary first to decide how the lab was to be used and then how it was to operate. These decisions determined the choice of equipment.

KEY WORDS: Language Laboratory design, language laboratory equipment, language laboratory management.
\end{abstract}

In 1982-83 Rockford College found itself in the same position as many other schools, struggling with the ruins of a twenty-year-old language laboratory that should have been mercifully put to rest years earlier. So we fought the battle for funding and won. We agonized over the choice of equipment and over the functions we wanted our new lab to perform and we could not be more pleased with what we have accomplished. Taking a practical, common-sense approach to the matter, and basing our choices upon our years of experience with our previous lab and the technology now available, we have designed what we believe is an ideal small language laboratory for the 1980's.

The first thing we had to do was choose equipment and we all agreed we wanted cassette tape decks: they are much more convenient than reel-to-reel and not about to become obsolete soon. From there our choice became confusing and difficult because of the large number of fine machines offered on the market. We solved the problem by deciding first how we wanted our lab to operate, and then by choosing the equipment that would best fulfill our objectives.

Earlier, during the time we were seeking funding for our lab, we were obliged to outline these objectives clearly because we discovered that we were being hindered by the fact that few people

Dr. James D. Gunn is Director of the Language Laboratory at Rockford College, Rockford, Illinois. 
outside our profession understand what a language laboratory is, does, and why it is so necessary for us in order to do the job of teaching a language effectively. The analogy I developed to help define and clarify the relationship of a language laboratory to language learning is somewhat simplistic, but it seems to work: language learning is the development of a skill and, as with any skill, a language can be learned only by repeated use. It is, for example, like the game of tennis. The tennis instructor will lecture on the rules of the game and the techniques of play, the students will read the text, and soon these students will know tennis. Now, this intellectualization of tennis is necessary, and it will make these students knowledgeable spectators, but they will not become accomplished players until they step onto a court, take ball and racket in hand, and practice what they have learned for many, many hours. This is equally true of a language, but because of the limits imposed by the number of students and by classroom time, actual use of the language in class by each student is not nearly adequate to produce students who can speak the language with any substantial proficiency. So the language laboratory is the place students must go to practice what they have learned in class and to develop the skills necessary to make them accomplished speakers of the language.

Since we recognized that frequent use of the language is essential for rapid acquisition of oral proficiency, we wanted to design a laboratory and a procedure for its operation that would maximize student contact with and use of the language. Part of the solution was to design a laboratory that would be interesting and convenient for students and would offer them a variety of activities for developing language skills. The other part of the solution was more problematic, and we saw two possible alternatives: we could create a lab in the library that would be available to students on a casual basis seven days a week during the hours the library was open (the students could check out tapes like they check out books and periodicals) and could supplement this with a few tape decks located in study rooms of some of the dormitories or we could create a more traditional lab capable of rapidly duplicating large numbers of cassette tapes that could then be distributed to students. Both of these plans would allow students to take out weekly practice tapes to work with at their convenience on their own machines and would maximize to the greatest degree possible the contact students would have with taped foreign language material. In the end we decided upon the second solution for the following reason. We require our students to make weekly student tapes--without the use of texts, workbooks, or any other aids--and to submit those tapes for evaluation by their instructors. Though this is a time-consuming task for the 
instructors, it is a very valuable one for our students and we did not want to give it up, nor did we want to surrender control over the manner in which students prepared their tapes. We needed a controlled environment.

It was apparent to us, from our experience with our old lab and from the rapid advances being made in technology, that we needed to find a way to forestall the obsolescence that would inevitably follow upon the heels of the acquisition of new equipment. Again, there seemed to be two alternatives: to purchase individual, autonomous tape decks that could easily and at moderate cost be replaced so that the lab would gradually keep pace with technology or to purchase one of the more advanced console-controlled laboratory systems. After some vacillation, we opted for the system. Though the autonomous tape decks would be cheaper, the cost of the high speed copiers required to produce the large number of tapes we would need each week would bring the final cost up into the neighborhood of the cost of a system without giving us the unique capabilities of the systems we were considering--such as monitoring and communicating with students through headsets, playing to individuals or groups from a source, complete control over the production of tapes for evaluation, and high-speed duplicating of master tapes in large quantities. Moreover, we discovered that the most advanced systems are micro-processor operated, which gives them the capability of being updated by a simple change of the electronic solid-state board that controls them.

We still had to decide between half-track and quarter-track machines. Again we vacillated, but we finally decided, despite some distinct advantages of the quarter-track (for example, one can flip the cassette over and record on both sides and one can listen to both the master and student tracks on a normal tape deck), that the half-track was here to stay for language labs because, we became convinced, it produces better-quality sound and would require less maintenance. In addition, with the quarter-track students could conceivably record on the student track on their stereo decks, thus circumventing our control over tapes produced for evaluation. With half-track machines they must use the lab to record onto the student track. On the other hand, there is a serious disadvantage with the half-track machines: there are no portable, inexpensive tape machines available for the use of instructors who want to evaluate student tapes conveniently since commercially available machines will play only the master track. There is an inexpensive machine of high quality that could work nicely for this purpose because it allows the user to switch between the upper and lower tracks, but it is available only to the blind. It is fortunate that such a machine cannot be readily purchased by our students, but it is most unfortunate that it is not available to language laboratories and language instructors. 
Our next step was to choose between transports to which our students would have direct access and transports to which they would have remote access--transports mounted in racks in the console room and operated remotely through student control panels located in carrels. We chose remote access for three reasons: less likelihood of damage to the equipment; greater control over the operation; and greater convenience to lab personnel, especially in the mass duplication of tapes.

Finally, related to our desire to maximize student contact with the language, we decided to vary the types of activities available in the laboratory. We purchased two microcomputers and, realizing good software was not to be had for foreign language study, we developed our own authoring program. Our students can now go to the computers to review vocabulary and to do any of the kinds of exercises we usually give our students: multiple choice, true/false, short answer, translations, fill-in-the-blank, change of word order or of tense, etc. They will be reinforced immediately, either negatively or positively, given the correct answer, and an explanation if the instructor wishes, and scored. We feel this use of the computers is effective and frees classroom time for other productive activities. In addition, we are purchasing automatic filmstrip and slide sound/ viewers, which are self-contained units, small enough to fit into a carrel, that can be used by one student with a headset viewing the 9X10 screen or that will project against a large screen for group viewing. We use these viewers with synchronized and pulsed foreign language tapes to present students with cultural materials assigned by their instructors and to increase, in an attractive and interesting way, their contact with the spoken language. The high quality and low cost of filmed material now available has made this option especially exciting to us and it has determined our next step, which will be the acquisition of a video cassette recorder and monitor so that we can take full advantage of the fine, convenient, and relatively low cost foreign language programs now being produced on video cassettes.

What we have now is a state-of-the-art remote-controlled language laboratory that will not become out-dated quickly, that performs all the functions we originally specified, that will perform functions we have not yet had the opportunity to experiment with, and that does a significantly more efficient job with more variety than our old lab with half the number of machines and less than half the space. But, really, the harder part of all this was setting up the day-to-day operation of this new lab.

The laboratory is run by student assistants who are on work/ study grants, who are at least sophomores, and are studying a language. They and the lab are under the authority of a full-time member of the language faculty. The operation works well because most of the assistants take pride in the job and an almost proprietary 
interest in the lab. Our foreign language students are charged a $\$ 10$ lab fee each semester to pay for the consumables and part of the operation. (A good quality tape, with ready-stick labels and a flexible cover to protect it, costs about a dollar). We prefer sixty-minute tapes (giving us thirty minutes of recording) since we feel student attention drops off quickly after about twenty minutes. Unfortunately, many of the commercially available tape programs are more than thirty minutes long and some are almost an hour. So we use some ninetyminute tapes too, but usually we cut longer tapes down to thirty minutes or less.

At the beginning of the semester each instructor makes up a lab schedule specifying the date each tape lesson will be available to his or her students and the dates when the tapes for evaluation are due. In most classes each student has two cassette tapes (marked "set 1" and "set 2") with the student's name, class, section, and instructor's name on the label. While the student has the set 1 tape out for practice, the following week's lesson is recorded onto set 2 . When the student feels prepared, and by the date specified by the instructor, the student will come into the lab, record onto the student track of tape 1, ask the lab assistant to submit that tape for evaluation, and pick up tape 2 . The procedure recurs every week, with a constant turnover of the two tapes.

We are also experimenting with other procedures. In some classes, for example, we give students a practice tape every week that prepares them for, but does not duplicate, the lab tape onto which they will have to record. (This lab tape never leaves the lab except for evaluation by the instructor.) Though the method is quite effective, it requires that each student have four tapes rather than two and that two master tapes be created for each lesson). Organizing this procedure so that it runs smoothly is difficult and initially it requires a lot of attention on the part of the director, but it works well, as demonstrated by the very favorable student reaction we have had. In my own classes, weekly lab use by students has gone from a painfully annoyed $40 \%-50 \%$ with our old lab to an approving and sometimes even enthusiastic $100 \%$ with our new lab.

Let me conclude my comments with a list of things one should do and look for when purchasing new language laboratory equipment. First, decide what functions you want the lab to perform and how you want it to operate. Next, pick equipment that will fulfill your objectives. Study the likelihood of instant obsolescence. Check to see if the company makes all its own equipment. If it farms much of it out, you are more likely to have trouble getting parts someday. Make sure service is readily available and/or that the company will train someone on your staff to maintain the equipment. Acquire a list of the institutions that have purchased the equipment you are interested in and ask them about their experience with it and why 
they chose it. Preferably, they should have had the equipment more than a year. Do not depend only upon the list given you by the interested company but solicit lists from competitors, too. Visit sites where the equipment is used. Let the companies you deal with know they are in competition--it is fierce--and with whom. You may get a better price, a better warranty, and other extras. And tinally, do not be totally logical. If the race is a close one, pick the equipment you feel most comfortable with. Remember, you are going to have to live with it for a long time.

\section{GENERAL PUBLICATIONS OF INTEREST}

\section{Travel and Learning Abroad}

Travel and Learning Abroad is a new bi-monthly magazine which features information and articles about international travel, exchange programs, study abroad, volunteer opportunities and special interest and non-formal learning opportunities. It also offers information about both individual and group travel and learning. The magazine is designed for the person who advises others about international travel and learning, as well as the individual who is seeking an in-depth experience abroad. Through feature articles, announcements, and advertising, readers learn about international exchange programs, study abroad programs, language study abroad, volunteer opportunities, and special interest travel. Charter subscriptions are available at $\$ 8.00$ per year (6 issues); $\$ 14$ for two years; and $\$ 18.50$ for 3 years. Single copies will be available on a limited basis through selected college and university bookstores for $\$ 2.00$ per issue. For subscription or additional information, contact:

Douglas Grube, Publisher

Travel and Learning Abroad

P.O. Box 1122

Brattleboro, VT 05301 